\title{
Desde las periferias de Santiago de Cali: una aproximación metodológica a la construcción de representaciones socioculturales y mediáticas por parte de grupos sociales subalternos en los medios digitales
}

\author{
Eliana Noscué Mera \\ Universidad Nacional de La Plata, Argentina \\ eliananoskwe@gmail.com \\ Leonardo Julio González \\ Universidad Nacional de La Plata, Argentina \\ leonardo.gonzalez@presi.unlp.edu.ar \\ Silvina Pauloni \\ Universidad Nacional de La Plata, Argentina \\ spauloni@hotmail.com \\ Recibido: 16/7/2018 / Aceptado: 5/2/2019 \\ doi: 10.26439/contratexto2019.n031.3890
}

\begin{abstract}
Resumen. El presente artículo describe las experiencias relacionadas con la construcción de representaciones socioculturales y mediáticas en los medios sociales digitales (Facebook, Instagram, YouTube) durante el desarrollo del proceso pedagógico de alfabetización digital denominado Alto Nápoles en Red. Dicho proceso es parte de las técnicas metodológicas utilizadas en una tesis doctoral en comunicación actualmente en construcción ${ }^{1}$. Estas técnicas cualitativas se
\end{abstract}

1 La tesis se ocupa de estudiar los usos y apropiaciones de las TIC digitales como construcción de representaciones socioculturales y mediáticas en los medios sociales por parte de poblaciones en situación de migración involuntaria o desplazamiento forzado, radicadas en las periferias de Santiago de Cali, Colombia. Una experiencia socioantropológica, comunicacional y pedagógica (2015-2017). 
desarrollaron con una comunidad migrante involuntaria y en situación de desplazamiento forzado, proveniente de las zonas rurales del suroccidente colombiano (departamento del Cauca) y radicada en una de las periferias de Santiago de Cali. Se trata de dar cuenta de las posibilidades, las resistencias y los obstáculos históricos por los que han transitado estos grupos sociales subalternos en el marco del conflicto interno armado en Colombia. Es decir, de conocer los usos y apropiaciones de las TIC digitales a partir de las diferencias culturales, las desigualdades socioeconómicas y las desconexiones mediáticas.

Palabras clave: grupos sociales subalternos / alfabetización digital / representaciones / periferias / medios sociales digitales

\section{From the peripheries of Santiago de Cali: a methodological approach to the creation of sociocultural and media representations by subordinate social groups in digital media}

Aвstract. This article describes the experiences related to the creation of sociocultural and media representations in digital social media (Facebook, Instagram, YouTube) during the development of the digital literacy pedagogical process called Alto Nápoles en Red. Said process is part of the methodological techniques used in a doctoral thesis in communication at present in construction. These qualitative techniques were developed with an involuntary-migrant community displaced by force from rural areas of southwestern Colombia (department of Cauca) and settled in one of the peripheries of Santiago de Cali. The paper aims to give an account of the possibilities, resistances and historical obstacles that these subordinate social groups have experienced in the framework of the internal armed conflict in Colombia. That is, its objective is to know about the uses and appropriations of digital ICT based on cultural differences, socioeconomic inequalities and media disconnections.

Keywords: subordinate social groups / digital literacy / representations / peripheries / digital social media 


\section{Introducción}

antiago de Cali es la capital del departamento del Valle del Cauca, ubicado en la zona suroccidental colombiana. Se le considera la tercera ciudad más importante después de Bogotá y Medellín por su número de habitantes, que supera los dos millones, y por su ubicación estratégica al ser la ciudad más cercana al puerto de Buenaventura, donde se administra más del 50 \% del comercio exterior ("Buenaventura lidera el comercio exterior", 1999).

El suroccidente ha sido una de las zonas más afectadas por el conflicto interno armado que se llevó a cabo a lo largo de la segunda mitad del siglo xx; el cual generó, desde 1985 hasta la actualidad, 7700000 desplazados forzados internos a nivel nacional pertenecientes a comunidades indígenas, afrodescendientes y campesinas mestizas ("Colombia sigue siendo el país con más desplazados internos: 7,4 millones", 2017). Los departamentos del Cauca, Nariño, Chocó y Valle del Cauca que componen esta zona se consolidaron como expulsores del $40 \%$ de poblaciones desplazadas ("Los departamentos de Colombia con mayor número de desplazados", 2016). De este porcentaje una gran mayoría llega a Cali convirtiéndola en una de las receptoras más representativas de este flagelo. En el año 2012 se indicó que más de 80000 personas registradas oficialmente como desplazadas ${ }^{1}$ residían en esta ciudad ("De cuatro millones de desplazados en Colombia, 80 mil viven en Cali", 2012).

Así, este territorio se ha configurado como una ciudad multicultural desde la desigualdad, la diferencia y la desconexión (García Canclini, 2004). Estos grupos sociales subalternos ${ }^{2}$, como se reconocen aquí por haber sido parte de diversas luchas sociopolíticas e históricas que los direccionaron a su situación actual, se han asentado en periferias reconocidas por altos niveles de pobreza y connotaciones negativas construidas en torno a las zonas territoriales y a las poblaciones

1 Muchas personas que atravesaron este flagelo no hicieron el reconocimiento ante el Estado por diversas razones como el temor a represalias por parte de los grupos ilegales. Entonces se infiere que existen muchas más personas en esta condición.

2 Se considera el uso de esta denominación conceptual a partir de los postulados teóricos que realizó el intelectual italiano Antonio Gramsci, en torno al reconocimiento de diversos grupos sociales insertos en estructuras de poder político, económico y sociocultural que devienen en diversas luchas simbólicas que definen la subalternidad y la hegemonía de dichos grupos sociales. Así entonces, teniendo en cuenta la historicidad social de estas poblaciones rurales y posteriormente urbanas periféricas, son reconocibles como grupos sociales subalternos insertos y condicionados por las estructuras de poder que han definido los grupos sociales hegemónicos y de élites tradicionales. Todo ello entendiendo que "El concepto de subalternidad se construye por ende tratando de entender tanto una subjetividad determinada como su potencial transformación por medio de la conciencia y la acción política" (Modonesi, 2010, p. 5). 
que las habitan. Los afrodescendientes provenientes del Pacífico, de zonas rurales y urbano-periféricas de Buenaventura (Valle), Chocó, Cauca y Nariño se han radicado al oriente de la ciudad, en el distrito de Aguablanca, y los campesinos mestizos e indígenas, principalmente provenientes del Cauca, se han asentado en laderas del suroccidente de la ciudad tales como Meléndez, Alto Nápoles y Siloé.

Debido a la amplia diversidad cultural y a la necesidad de reconocimiento de derechos que se les debe históricamente a estas comunidades, ha sido indispensable preguntar sobre el estado actual de las representaciones socioculturales ${ }^{3}$ que pudiesen estar construyendo en los medios sociales. Es decir, la construcción de memoria histórica en constante deconstrucción y reconstrucción identitaria a partir de los usos y apropiaciones de las Tecnologías de la Información y la Comunicación Digital (TIC-D) que aporte a la representación mediática ${ }^{4}$ de la ciudad, donde se

3 Se reconoce la representación como concepto interpretado teóricamente desde acepciones con tradiciones lingüísticas (Saussure/Barthes), discursivas, socio-políticas (Foucault/ Gramsci), para luego complementarlo desde la interpretación del concepto de cultura como resultado de la construcción de prácticas de significación (fuertemente sedimentadas) presentes en todo proceso social que es posible por lo territorial, lo político y lo económico (Grimson, 2011) además de lo tecnológico, tal como se plantea en esta investigación. Así, para interpretar la representación como concepto desde una acepción básica, es válido decir que "Representación significa usar el lenguaje para decir algo con sentido sobre el mundo, o para representarlo de manera significativa a otras personas." (Hall, 2010, p. 447). Todo lo que produce las representaciones simbólica y materialmente en el mundo social, sucede a partir de la construcción de "prácticas de significación" (Grimson, 2011) presentes en todo proceso social que forma parte de "lo político", "lo económico" y "lo cultural" no "como esferas ontológicas" (Grimson, 2011) sino como estructuras dinámicas en las que se desarrollan las realidades sociales.

4 Se reconoce el concepto de representación mediática como "[...] representaciones producidas por los medios de comunicación, entendiéndolos como operadores de visibilidad y traducibilidad, y responsables junto con otros sistemas simbólicos de trazar mapas, organizar y engarzar el ordenamiento social histórico en la dimensión de la cultura" (Cebrelli y Rodríguez, 2013, p. 90). Es decir, espacios para comunicar, poner en común y en ese mismo proceso disputar la posibilidad de contarse y representarse más allá de esos procesos constitutivos históricamente donde los medios de comunicación masivos han visibilizado lo invisibilizado desde representaciones estigmatizantes, al punto de consolidar una ilusión de realidad. Entonces esta producción representacional mediática es posible no solo a una dimensión productiva (Charaudeau) sino también a una dimensión maquínica (Grossberg) y los procesos discursivos (Foucault) editoriales y visuales.

De todas formas, la complejidad del asunto representacional mediático no radica en que se amplíen los escenarios o las plataformas mediáticas para garantizar una democratización y pluralidad de voces subalternas, pues es factible que se reemplacen modos de segregación históricos por otros emergentes que cristalicen los estigmas. "Pues, pese a la indudable potencia hegemonizadora de la máquina mediática, es posible pensar en la irrupción de la voz y la mirada de los subalternos, a través de los discursos mediáticos, contaminando o re-organizando las representaciones hegemónicas y cambiando las valencias" 
incluya a las periferias y sus formas de vida; aquellas que generalmente son excluidas de los folletos turísticos y del discurso institucional hegemónico.

Esta pregunta se plantea en el marco de una investigación doctoral en comunicación que propone un estudio exploratorio analítico sobre los usos y apropiaciones de las TIC-D vinculadas a la producción, difusión y visualización de productos audiovisuales en los medios sociales por parte de estas poblaciones. Se plantea conocer las formas en que se construyen representaciones sociales y mediáticas como productores, usuarios y consumidores en los medios sociales.

Cabe aclarar que la metodología aplicada en la investigación ${ }^{5}$ es mucho más amplia de lo que se expone en el presente texto. Se compone de un trabajo de campo etnográfico que contiene encuestas, entrevistas semiestructuradas, observación participante y el desarrollo de un proceso pedagógico de alfabetización digital $^{6}$. Este último arrojó datos puntuales sobre el tema que aquí atañe referente a la incorporación de productos audiovisuales (fotos, videos, gif, memes, etcétera) como construcción de representaciones mediáticas de la comunidad desde las zonas periféricas de la ciudad.

Fue posible conocer sobre las características de acceso a los dispositivos y a las conexiones que les permiten, intermitentemente, ser parte de la sociedad mediatizada aunque desde las diferencias históricas que los definen; conocer sobre los usos y apropiaciones que hacen de los dispositivos y de los medios sociales. En ese sentido fue importante encontrar, que si bien el rol de prosumidores ${ }^{7}$ es incipiente por las desigualdades de acceso y/o alfabetización digital ${ }^{8}$; las acciones

(Cebrelli y Rodríguez, 2013, p. 96). Máxime en los nuevos escenarios digitales. Más allá de proponer revisar la incidencia representacional mediática de estos grupos sociales subalternos en los medios conectivos digitales se trata de conocer los procesos sociotécnicos y culturales que anteceden y circundan la visualización, difusión y producción de productos audiovisuales entendidos como bienes simbólicos.

5 Esta investigación se hace en el marco de la Beca Doctoral Latinoamericana 2015-2020 otorgada por el Consejo Nacional de Investigaciones Científicas y Técnicas (Conicet).

6 El proceso de alfabetización digital fue financiado por la Secretaría de Cultura del gobierno municipal de la ciudad a través de la Convocatoria Estímulos Cali 2017.

7 Se explicita que el reconocimiento que se hace de este concepto en esta investigación, está intrínsecamente relacionado con el concepto de cultura participativa propuesto por Jenkins (1992), a partir del cual se plantea una oposición entre la industria de los medios y la actividad colaborativa de individuos insertos en grupos o redes amplias, desde donde les es posible propagar contenido más allá de su proximidad geográfica. Es decir, el reconocimiento de valor simbólico y de disputa representacional a partir de la producción de bienes culturales en los espacios digitales.

8 Se reconoce la alfabetización digital como un proceso pedagógico direccionado a la comprensión y posterior utilización del lenguaje multimedial, es decir, un proceso que 
que llevan a cabo en estos espacios y con estas herramientas poseen amplias referencias a sus recursos simbólicos y biográficos; es decir, a sus historias de vida antes del desplazamiento o la migración, a su cosmovisión, saberes ancestrales relacionados con la gastronomía, la organización comunitaria, con sus formas de vida rurales que ahora son parte de las periferias urbanas. La experiencia pedagógica desarrollada evidenció que al atender la importancia de inclusión digital por parte de Estados y gobiernos existen altísimas posibilidades; seguro que no para acabar con la amplísima brecha digital que está relacionada con las desigualdades históricas de las que han sido parte estas comunidades, pero sí para garantizar mínimamente el derecho a la información y la comunicación que actualmente es transversal a los medios sociales digitales.

\section{Discusión teórico-empírica}

Cada vez que alzo la vista y veo la pantalla, el mundo de las redes sociales y de la socialidad online ha cambiado, obligándonos a formular una nueva interpretación.

Van Dijck (2016)

\section{Redes virtuales $\neq$ redes comunitarias}

Alto Nápoles es una amplia zona periférica ubicada al suroccidente de la ciudad, compuesta por distintos barrios que se fueron conformando irregularmente durante el último cuarto del siglo xx y lo que va del xxi. Esta conformación social y territorial ha sido caracterizada por aspectos rurales que traen consigo los grupos subalternos que migran involuntariamente o se desplazan forzosamente desde el suroccidente colombiano, principalmente desde el departamento del Cauca.

La comunidad puntual con la que se desarrolla esta investigación proviene de municipios del Departamento del Cauca tales como Buenos Aires, Caldono y

conlleve a "la capacidad de comprender y utilizar la información de fuentes diversas y múltiples formatos, cuando se presenta a través del ordenador" (Gutiérrez Martín, 2003, p. 4) y los dispositivos móviles. Asimismo, se resalta la necesidad de rescatar y vincular las particularidades históricas socioculturales, educacionales y de acceso a las TIC que han tenido los grupos sociales con los que se desarrolle el proceso pedagógico. Esta recomendación pedagógica direccionada a la emancipación y organización social se reivindica desde los postulados de la educación popular y decolonial propuesta por autores como Paulo Freire y Catherine Walsh (2003). 
La Vega. En estas zonas existen diversos cabildos indígenas por lo que muchas de las personas con las que se trabajó pertenecen a las comunidades yanacona y nasa. El sector donde se asentaron en la zona periférica caleña es denominada por ellos mismos como Brisas de Alto Nápoles; asimismo es necesario mencionar la zona denominada como Bosques 1 y 2, ya que es la zona aledaña y en conjunto suman 2000 personas aproximadamente. Cabe aclarar que Bosques 1 y 2 cuenta con 20 años de historia y Brisas de Alto Nápoles con una más reciente de ocho años.

Esta última experiencia de conformación territorial, por estar más cerca en el tiempo, permitió conocer por relatos de sus protagonistas los diversos procesos que han llevado a cabo para la construcción de sus casas, la incorporación de la energía, el alcantarillado, el agua y la pavimentación de calles y andenes. Para lograrlo, esta comunidad prioriza la minga o minka que implica la cooperación de todos los habitantes en una actividad de trabajo que conlleve a un bien común.

Gracias a las mingas, en ocho años Brisas de Alto Nápoles pasó de ser una ladera inhabitada a una zona en constante construcción territorial e identitaria que emana la ruralidad y las prácticas culturales propias de los pueblos campesinos, aunque estén ubicados a 15 minutos de una de las principales autopistas de la ciudad.

Por todas estas características es necesario problematizar la generación de conocimiento sobre los usos y apropiaciones de las TIC, ya que "gran parte de la producción académica que las vincula con el territorio tiene como ámbito de observación y análisis a las áreas metropolitanas de economías avanzadas" (Vio y Fritzsche, 2007, p. 64) y no se vinculan las experiencias que se viven y se proponen desde las periferias. De todas formas no se trata de debatir sobre "el lugar central de la producción y también del intercambio de información" (Vio y Fritzsche, 2007, p. 50) con el que es percibida la ciudad y su centro de producción al utilizar las TIC como herramientas para la acumulación de capital.

Se trata más bien de conocer, en primera instancia, las características propias de un territorio en construcción y sin reconocimiento gubernamental que evidencia los flagelos sociales más profundos con los que han convivido los colombianos excluidos: la pobreza económica, la falta de educación formal, la falta de infraestructura y servicios básicos, pero también la evidencia de la organización social y comunitaria que sobrevive al desplazamiento y al cambio abrupto de su territorio natal, que se encuentra inscrito en la memoria histórica de estos pueblos.

9 Minka es un concepto propio del idioma del pueblo indígena yanacona del Cauca, al cual pertenecen muchos habitantes de Brisas de Alto Nápoles. 
En ese sentido es necesario resaltar la importancia que tiene el término de red en este estudio que, según Quintar, en las ciencias sociales "[...] es inicialmente utilizado por los análisis acerca de los mecanismos de supervivencia básicos desarrollados por grupos poblacionales marginados" (Quintar, 2007, p. 72). También, apunta el autor, esta noción se relaciona con la articulación de movimientos sociales vinculados a los campos políticos y culturales para consolidarse en redes mucho más amplias que pueden llegar a constituirse en redes internacionales.

La organización política de una red prioriza la voz asamblearia de quienes la conforman, es decir que se construye un orden horizontal asambleario; sin embargo, cuando se consolida la conformación de una red de redes es posible que se proponga un centro de coordinación que articule en pos de los objetivos que convocan a los sujetos sociales que conforman dichas redes.

Este tipo de organización política y social propia de la noción de red es la que se aplica empíricamente en esta comunidad. Cuestiones que aportan al territorio una hibridación cultural (la relación corporal con la música, la estética, las relaciones familiares y sociales) e histórica; sin embargo, las diferencias que existen entre estos grupos sociales (indígenas, afrodescendientes, campesinos mestizos) pasan a un segundo plano al priorizar las necesidades comunes del territorio. Es característico en la red de trabajo comunitario que se ha conformado que la producción sea lenta en comparación con los modos de producción del sistema capitalista y neoliberal, ya que los trabajos comunitarios se realizan los domingos, día en el que se encuentran descansando de sus trabajos no calificados o desconectados de la sociedad y la economía de la información, tales como los empleos de vigilantes, obreros rasos, empleadas de servicio doméstico y vendedores ambulantes.

Pues bien, sería factible pensar que estas propiedades teóricas y empíricas sobre la red comunitaria offline son fácilmente extrapolables a la noción de red digital, tal como lo señalaba Tim Berners-Lee, el creador de la red World Wide Web más, conocida como la Web 1.0 o la Web pasiva. Esto teniendo en cuenta una entrevista del año 2000 donde resaltaba que el "carácter abierto y descentralizado de la Red permitió que la misma se expandiera rápidamente sin necesidad de contar con alguna autoridad centralizada para desarrollarse" (Quintar, 2007, p. 76).

Así entonces, "la creencia de que la web 2.0 era un espacio comunitario y de colaboración inspiró en aquellos tiempos a muchos entusiastas a trabajar en la construcción de distintas plataformas, y algunos ecos de este espíritu resuenan aún hoy" (Van Dijck, 2016, p. 28). Sin embargo, el nuevo milenio trajo consigo la infraestructura de la Web 2.0 o la Web Social y con ella pocas empresas que posteriormente se convirtieron en corporaciones (Google, Apple, Amazon, Facebook) 
dedicadas a la producción de plataformas propias que se ofrecieron para ser "las intermediarias para la trasmisión de datos de comunicación y de información" (Van Dijck, 2016, p. 21).

Fue así como se achicó la esperanza democratizadora que los medios sociales traían consigo para superar la temible homogeneización social de los medios masivos y hegemónicos del siglo xx. Tanto se ha achicado el enfoque de la producción colaborativa y la comunicación participativa que los avances tecnológicos que se tienen de la Web 3.0 o la Web semántica están intrínsecamente relacionados con la monetización de los datos y los metadatos de los usuarios a nivel global, es decir, con la utilización de estos, autorizada por el usuario, con fines de explotación comercial.

A pesar de esta capitalización de los medios sociales o conectivos como prefiere llamarlos Van Dijck (2016), se coincide aquí con las y los investigadores que sostienen que "las plataformas de medios sociales han introducido un espacio dentro del cual se desdibujan los límites entre lo público y lo privado", asegurando que "esta imprecisión abre nuevas posibilidades para la conformación de identidades" (Van Dijck, 2016, p. 37) y subsecuentes representaciones sociales y mediáticas.

\section{Las diferencias y las desigualdades}

Hace más de una década Néstor García Canclini propuso un análisis que articuló tres nociones clave en las ciencias sociales cuando de procesos culturales se trata. Problematizó las antropologías de las diferencias, las teorías sociológicas de la desigualdad y los estudios comunicacionales sobre las conexiones y las desconexiones mediáticas.

En ese sentido fue fundamental comprender que es más importante "prestar atención a las mezclas y los malentendidos que vinculan a los grupos" (García Canclini, 2004, p. 21) que comparar las diferencias y justificarlas en el relativismo cultural:

Al conceptualizar la cultura de este modo, estamos diciendo que la cultura no es apenas un conjunto de obras de arte, ni de libros, ni tampoco una suma de objetos materiales cargados con signos y símbolos. La cultura se presenta como procesos sociales, y parte de la dificultad de hablar de ella deriva de que se produce, circula y se consume en la historia social. No es algo que aparezca siempre de la misma manera. De ahí la importancia que han adquirido los estudios sobre recepción y apropiación de bienes y mensajes en las sociedades contemporáneas. Muestran cómo un mismo objeto puede transformarse a través de los usos y reapropiaciones sociales. Y también cómo, al relacionarnos unos con otros, aprendemos a ser interculturales. (García Canclini, 2004, p. 34) 
Entonces lo de aprender a ser interculturales, en el proceso que se expone aquí, fue una premisa que conllevó a tener muy en cuenta cómo dicha comunidad ha construido su red comunitaria. Todo ello reconociendo que es una comunidad culturalmente híbrida. En apariencia se podría pensar que, al tener condiciones económicas y sociales similares, era factible la existencia de una armonía política si se tiene en cuenta que su organización comunitaria tiene muy claros sus objetivos tangibles. Sin embargo, las complejidades culturales que pudiesen impedir una organización comunitaria más sólida estaban relacionadas con la alteridad: la dificultad de reconocimiento de las particularidades culturales de quienes provienen de las zonas rurales y los cabildos indígenas y que devienen en formas y maneras propias de organización política y ejecución de proyectos.

Como se dijo, la zona Bosques lleva mucho más tiempo de constitución que Brisas de Alto Nápoles. Es por ello que los habitantes de Bosques, campesinos mestizos y ciudadanos periféricos con mucho más tiempo de convivencia en la ciudad, califican como extrañas las formas de organización política de los indígenas llegados hace ocho años. Así, estos últimos, a partir de sus tradiciones político-culturales, proponen organizaciones cabildantes o de comisiones para facilitar las mejoras territoriales. Esto es desconocido u olvidado por quienes han aprehendido formas de acción o inacción política urbana, es decir, consideraciones más individualistas. Por ello, los líderes de Bosques manifestaron la necesidad de que los indígenas abandonaran sus formas de organización y aprehendieran, como ellos lo hicieron, las nuevas dinámicas que según ellos exige la ciudad.

Es así como se evidencia que al interior de estas dos zonas son ubicables cinco subgrupos sociales. Por una parte los vecinos mestizos que son representados por líderes comunitarios históricos que han sido parte de las Juntas de Acción Comunal $(\mathrm{JAC})^{10}$; el Cabildo Nasa de Alto Nápoles ${ }^{11}$ que representa a la comunidad nasa de la zona; los líderes de Brisas de Alto Nápoles que es la zona habitada mayoritariamente por indígenas del pueblo yanacona ${ }^{12}$; los afrodescendientes que son familias numerosas, y los autodenominados organizados, un grupo compuesto por indígenas, campesinos mestizos y afros que viven juntos en una zona determinada.

Estas disimilitudes generadoras de tensiones y desencuentros al interior de esta red comunitaria evidencian lo que García Canclini (2004) denomina una

10 Las Juntas de Acción Comunal son organizaciones barriales reconocidas legalmente para recibir y distribuir recursos públicos.

11 El Cabildo Indígena Nasa Alto Buenavista no es reconocido por el gobierno municipal como cabildo urbano porque argumentan que ya hay reconocimiento de un cabildo urbano nasa que debe acoger a todos los nasa residentes en Cali.

12 La comunidad yanacona no busca ser reconocida como cabildo. Se adhieren al Cabildo Urbano Yanacona de Cali. 
"problemática de la diferencia", visible principalmente en las prácticas culturales y políticas:

La absolutización se presenta con dos movimientos, por una parte, se distinguen como exclusivos de los pueblos indígenas sus lenguas y ciertos "valores": la reciprocidad de las relaciones comunitarias, el trabajo no remunerado, sistemas normativos propios, relaciones sociales gobernadas por regímenes de autoridad, costumbres alimentarias originadas por el arraigo en el territorio tradicionalmente ocupado por cada grupo. Al mismo tiempo, se define a esos rasgos como inalterables y se actúa para darles continuidad. (García Canclini, 2004, p. 47)

La desigualdad social que une a estos subgrupos es fragmentada por las diferencias culturales que los identifican y complejizan el fortalecimiento de ese proceso emergente, propio "de proyectos germinales, que son diferentes del proyecto que se está tratando de plantear como homogéneo y como hegemónico" (Bonfil, cit. en García Canclini, 2004, p. 51).

\section{La periferia y la desconexión}

El acceso material a la tecnología está intrínsecamente relacionado con el acceso al capital monetario que garantizaría la compra de dispositivos y de acceso a redes ${ }^{13}$. Entonces es fácil concluir que la desigualdad social conlleva a la desconexión y a la "desigual participación en las redes de información [que] se combina con la desigual distribución mediática de los bienes y mensajes de aquellas culturas con las que estamos interactuando" (García Canclini, 2004, p. 190). Sin embargo, lo importante aquí es conocer las particularidades de dicha desconexión que ha sido perpetuada por el destiempo con el que este tipo de comunidades ha transitado los usos y apropiaciones de las TIC analógicas y actualmente de las TIC digitales. Esa desconexión con la sociedad del conocimiento y la información ha conllevado también a la continuidad de las formas de organización comunitaria y política que se ha venido retratando y a singulares experiencias simbólicas con las TIC:

Al observar la variedad de compromisos identitarios y de modos de simbolizar el sentido social, comprobamos que los conocimientos necesarios para situarse significativamente en el mundo deben obtenerse tanto en las redes tecnológicas globalizadas como en la transmisión y reelaboración de los patrimonios históricos de cada sociedad. (García Canclini, 2004, p. 189)

13 Colombia no cuenta con una política pública como lo fue el Plan Ceibal en Uruguay o el Plan Conectar Igualdad en Argentina. 
Es por ello que se propone la importancia de la alfabetización digital como acceso a un conocimiento que ofrece herramientas para el desarrollo de representaciones sociales como productores, difusores y usuarios, y de la construcción de representaciones mediáticas en los medios sociales. Todo ello en articulación con las particularidades que estas poblaciones han tenido con las TIC en sus lugares de origen rural y posteriormente en la periferia de una ciudad.

En Colombia las grandes extensiones rurales complejizan incluso la conexión territorial y de vías, por lo que ha sido la radio analógica el medio de comunicación por antonomasia y, en menor medida, los televisores analógicos con señales de televisión abierta. El acercamiento a los celulares inteligentes, los computadores y el acceso a internet suceden principalmente cuando estas comunidades llegan a la ciudad.

Con este panorama es necesario consolidar hábitos de conocimiento que generen el entusiasmo por ser prosumidores y produsuarios, y en ese accionar fortalezcan la denominada segunda oralidad. Es decir, la posibilidad de registrar en soportes audiovisuales y narrar (haciendo uso de las plataformas digitales) a redes externas sus procesos comunitarios.

En ese sentido García Canclini se pregunta "qué logran estas incorporaciones ocasionales, relativamente aisladas a las redes avanzadas del conocimiento" (2004, p. 189), a lo que algunos académicos contestarán que no serviría de mucho si se tiene en cuenta que, en plataformas como YouTube, investigaciones demuestran que:

[...] menos del 20\% de los visitantes de YouTube son activos proveedores de contenido, y que el $20 \%$ de estos colaboradores cargan el $73 \%$ de los videos [...]. En otras palabras, un $4 \%$ de los usuarios de YouTube brinda casi tres cuartos del contenido del sitio, y, por si fuera poco, estos colaboradores activos no son demográficamente representativos en términos de edad y género. (Van Dijck, 2016, p. 191)

Además, los algoritmos de estas plataformas potencializan personas (perfiles) y contenidos por encima de otros muchos, direccionando tendencias/viralizaciones y construyendo influenciadores. Por lo que queda claro que los objetivos de la conexión desde las periferias y por los grupos sociales subalternos que las habitan no pasa por las dinámicas de las corporaciones propietarias de los medios sociales. Se trata de producir y compartir documentación audiovisual que aporte a la memoria histórica y a la historia social subalterna, la cual difiere en gran medida de la historia social hegemónica construida por los grupos sociales dominantes.

En ese sentido es debatible que "la internet permite establecer una comunicación sin jerarquías, lo que en términos políticos puede traducirse como una 
comunicación democrática" (Calello y Fritzsche, 2007, p. 86). Esto si se piensa en los alcances de internet a nivel global o masivo. Además se estaría obviando que en pleno siglo xxi muchas comunidades siguen desconectadas por la falta de acceso material a los dispositivos y a las redes y carecen de alfabetizaciones propias sobre el funcionamiento corporativo de los medios sociales. Generalmente estos conocimientos de uso y apropiación son empíricos y en destiempo en comparación con aquellos que consolidan las clases sociales medias y altas. Sin embargo, sí es posible "construir espacios de debate alternativos y de articulación de las acciones que llevan a cabo los movimientos sociales" (Calello y Fritzsche, 2007, p. 86).

Existen antecedentes históricos como el movimiento zapatista en México, los organizados Sin Tierra en Brasil, las Madres y Abuelas de Plaza de Mayo en Argentina y la comunidad nasa en Colombia, desde donde se han desarrollado procesos comunicacionales relevantes para la organización social y comunitaria. Es entonces cuando se debe destacar que el afianzamiento comunicacional de organizaciones sociales, políticas, barriales y comunitarias constata que las TIC-D son herramientas que, en primera instancia, fortalecen los lazos preexistentes al interior de las organizaciones para luego confortar las posibles articulaciones y divulgaciones a nivel glocal. Pero para que esto suceda los sujetos que componen los movimientos periféricos deben acceder a la alfabetización digital desde las resistencias. Superar la ausencia de dispositivos de alta tecnología y de las redes telemáticas que el Estado debe suplir a partir de una verdadera voluntad política que supere el determinismo tecnológico ${ }^{14}$. Es decir que las posibilidades de evidenciar, comunicar e informar sobre la organización comunitaria, sus proyectos y las exigencias a gobiernos y al Estado en pos de su buen vivir, deben pensarse desde las posibilidades reales: desde la complejidad, las ausencias, las resistencias, las precariedades, las hibridaciones, las desterritorializaciones y territorializaciones en construcción.

\section{Metodología}

El umbral teórico de esta investigación propone que las TIC o alguna otra tecnología no tienen vida propia o poderes absolutos manipulatorios; tampoco que las

14 Así como no es sensato esperar del incremento de conexiones la desaparición de las diferencias, tampoco podemos esperar que elimine las desigualdades. Reducir la brecha digital puede aminorar algunas desigualdades, ante todo las que generan el acceso inequitativo a los mensajes y bienes ofrecidos en el ciberespacio. Pero en la medida en que una distribución menos desigual de la riqueza mediática y digital implicaría, como dijimos, mayor multilingüismo y policentrismo, es previsible que se fortalezcan las diferencias y persistan desigualdades asociadas a ellas (García Canclini, 2004, p. 194). 
tecnologías surgen al margen de las necesidades sociales, políticas y económicas de una sociedad:

Las tecnologías son habilitantes (e inhabilitantes), más que determinantes. Aparecen, existen y desaparecen en un mundo que no es del todo obra suya [...] las tecnologías son cosas sociales, impregnadas de lo simbólico y vulnerables a las eternas paradojas y contradicciones de la vida social, tanto en su creación como en su uso. (Silverstone, citado en Winocur y Sánchez Vilela, 2016, p. 26)

Sí se reconoce que el desarrollo tecnológico está intrínsecamente relacionado con las características de la inserción social que se define por procesos simbólicos en diálogo con contextos puntuales por determinados actores sociales; es necesario definir que el proceso metodológico debe priorizar una:

[...] aproximación metodológica que analice los procesos tecnológicos en donde están ocurriendo [lo que] nos conduce a la construcción de nuevos conceptos y categorías de análisis, que tienden puentes que superan las dicotomías ciegas con que hasta ahora hemos tanteado el tema de las nuevas tecnologías. (Santos y Márquez, 2003, p. 79)

Máxime cuando se pretende que los aportes teóricos y metodológicos incluyan las evidencias obtenidas en contextos sociales particulares, históricamente marginados, que generalmente son excluidos de lo que definen el conocimiento y la ciencia. Es decir que lo aportado aquí amplía los conocimientos sobre los usos y apropiaciones de las TIC, que difieren ampliamente de las investigaciones basadas en estudios con poblaciones actualizadas, conectadas y pioneras en los accesos a las tecnologías digitales.

Hay antecedentes de investigaciones que concluyen "que no basta comprar y distribuir equipo informativo" (Winocur y Sánchez Vilela, 2016, p. 13) para garantizar la apropiación digital por parte de familias pobres; es necesario asumir un camino intermedio que no desconozca la potencialidad de los sectores populares.

La construcción de representaciones sociales y mediáticas de estos grupos poblacionales en los medios sociales está mediada por los alcances tecnológicos de los aparatos que generalmente son escasos y caracterizada por la desigualdad de la alfabetización digital. Pero no se puede obviar el valor simbólico, estético, organizacional y político que aporta la producción audiovisual (fotos, videos, gif, memes, etcétera) en los nuevos medios a las luchas sociales y políticas históricas en América Latina. Las clases populares cuentan con influencias coloniales, andinas, afro, campesinas, indígenas; todo ello atravesado por la globalización de modelos neoliberales y capitalistas:

[...] los obstáculos solo se piensan como la dificultad de asimilar un conocimiento nuevo y complejo, omitiendo el hecho de que la incorporación de 
cualquier medio de comunicación siempre ha estado mediada por las representaciones sociales que cada grupo o segmento social han construido históricamente con la tecnología, a partir de una apropiación muy desigual de sus posibilidades. Lejos de ser una hoja en blanco, las familias procesan y filtran las novedades tecnológicas a partir de sus universos simbólicos de pertenencia y experiencia con otras tecnologías. (Winocur y Sánchez Vilela, 2016, p. 26)

La construcción de representaciones sociales y mediáticas es en demasía compleja, no solo por la apropiación desigual de las TIC, sino también por las posibilidades de autorepresentación histórica que les ha sido negada a las clases populares en América Latina.

En el caso colombiano existió una relación intrínseca entre la epistemología y la escritura de la historia que permite comprender y reconocer "el impacto del racismo en la construcción de alteridades racializadas", entendiendo "que el acceso a la palabra escrita evidenciaba un ejercicio de poder, puesto que el poder nombrar o clasificar la realidad es un modo de poseerlo lingüística y simbólicamente" (Vega Bendezú, 2013, p. 19). Las élites criollas lograron construir representaciones sociales que connotan los grupos subalternos con adjetivos negativos y de ausencias simbólicas, sociales y políticas.

Por ello la metodología aplicada en estos procesos de investigación debe priorizar el análisis sobre los procesos prácticos y simbólicos que estas comunidades hacen de las TIC, por encima de los planteamientos teóricos que priorizan las posibilidades para acceder a la sociedad de la información, como la solución a la inclusión laboral y productiva y/o el mejoramiento a la calidad de vida que permitiría el ascenso social, tal como lo propone el Ministerio Tic en Colombia.

El proceso pedagógico de alfabetización digital como espacio generador de experiencias conjuntas de enseñanza-aprendizaje se caracteriza por el reconocimiento de territorialización híbrido. Exige que cada actividad se articule con las tecnologías de las que se pretende reflexionar y con las características propias de procesos sociales y culturales que caracterizan a la comunidad.

Es necesario deconstruir los postulados clásicos de la pedagogía positivista basados en diagnosticar el nivel de conocimiento de los sujetos a alfabetizar, para luego clasificarlos y a partir de allí comenzar a transmitir el saber. Por el contrario, se debe tener en cuenta, por un lado, La pedagogía del oprimido propuesta por el pedagogo Paulo Freire (2005). A partir de ella se reivindica la necesidad de reconocimiento y pertenencia a una determinada clase social como andamiaje de lucha y organización social y política. Camino emancipatorio y libertario. Es decir, el reconocimiento de la importancia de la construcción de resistencia, autonomía y libertad: 
La pedagogía no está limitada a la institución de la educación, si hablamos de pedagogías en general, podemos decir que las luchas que ejercen los movimientos, los colectivos, barrios populares, etc.; muchas veces ejercen un tipo de pedagogía, hacen un tipo de acción - reflexión, la acción para actuar de mejor manera, un continuo proceso de aprendizaje, de desaprendizaje, de reaprendizaje. [...] pedagogías como metodologías indispensables, necesarias para la transformación social. (Walsh, 2017)

Por otro lado, la pedagogía decolonial que prioriza el reconocimiento del lugar desde donde se está pensando el conocimiento: América Latina. Se busca la apertura de perspectivas distintas, a partir de procesos continuos en comunidades puntuales que aporten desde sus propias historias y memorias la construcción del conocimiento. "Lo decolonial no necesita un autor, un manual, recetas o esquemas que digan así es la forma; sino que se trata de ir cuestionando y preguntando continuamente y reconocer que existe una estructura de poder" (Walsh, 2017).

Con estos antecedentes teóricos, los datos y las experiencias preexistentes construidas con la comunidad, se dio paso a la construcción de los contenidos del proceso pedagógico.

Por ejemplo, fue importante tener en cuenta la problemática que buscaban solucionar en ese momento (febrero-octubre del 2017). Se trataba de la pavimentación de la carretera de acceso principal a la zona que impedía el ingreso y salida de vehículos en situaciones de urgencia. Teniendo en cuenta que sus prioridades radican en cuestiones tan básicas como el acceso a su vivienda, la obtención de un empleo, la educación básica, su alimentación e incluso la construcción de sus casas, era complejo proponerles la importancia de la construcción de representaciones mediáticas en los medios sociales, entendiéndolos también como espacios de visibilización y lucha. Fue indispensable reflexionar en conjunto con los adultos sobre los usos y apropiaciones que desarrollaron con las TIC precedentes. Con esto se buscaba acercarlos a las nuevas tecnologías, que reflexionaran sobre la posibilidad de fortalecer sus cotidianidades comunicativas digitales. Como se esperaba, fue mucho más fluido el intercambio de experiencias con los jóvenes y los niños, quienes acceden más cómodamente a las dinámicas de la digitalidad.

Se propusieron 10 encuentros, cada fin de semana, de tres horas cada uno, en un salón comunal en construcción que cobró un valor simbólico y funcional por parte de la comunidad. Los requerimientos técnicos y logísticos que exigió cada sesión fueron gestionados por quien investigaba pero también por líderes de la comunidad.

Fue revelador que un proceso pedagógico de alfabetización digital no se destacara por la presencia de tecnología sino que, por el contrario, emergiera en 
ese espacio físico la estética rural y las dinámicas propias de mingas o encuentros comunales. Las conversaciones grupales entre mujeres, la importancia de la comida para los niños, la introducción al espacio de tareas como el tejido y la elaboración de artesanías en medio de los ejercicios propuestos.

El desarrollo de los contenidos se dividió en tres bloques, focalizados siempre en ocupar la primera parte de las sesiones en las discusiones teórico-experienciales. Se iniciaba con los aspectos teóricos sobre los medios comunicacionales; para que, durante dicha exposición, en conjunto con los asistentes, se dialogara sobre las experiencias que individual, familiar y comunitariamente habían tenido con las TIC.

Para la segunda parte de las sesiones se proponía la puesta en práctica de la interacción con sus propios dispositivos. La cantidad de asistentes variaba semanalmente entre 25 y 30 personas. Algunos no poseían un dispositivo propio por lo que era necesario consolidar equipos de trabajo.

En el primer bloque se estudió la historicidad y el desarrollo tecnológico de las TIC. Pasando por la oralidad y la escritura, la prensa, la radio y la televisión analógicas y finalmente internet; donde se concluyó que convergen todas las anteriores y las nuevas que se catalogan como medios sociales. Se propuso comprender que las TIC no tienen fecha de vencimiento, ni paredes divisorias entre unas y otras. Se reconoció que el destiempo con el que estas poblaciones han llegado a la interacción y posterior utilización de las TIC-D es abismal. Por ejemplo, aunque Facebook y YouTube funcionan desde los años 2004 y 2005 respectivamente, fue solo hasta hace poco más de un par de años que estas poblaciones conocieron sobre su existencia. Por su parte, la televisión por demanda como Netflix solo está dentro de su universo simbólico efímeramente. Por eso en una de las sesiones visualizaron el episodio "Caída en picada" de Black Mirror (Jones y Schur, 2016). Las críticas al comportamiento desmedido de la protagonista en sus redes sociales digitales no se hicieron esperar.

Durante el inicio de este primer bloque se revisaron las representaciones mediáticas de la comunidad existentes en los medios sociales, puntualmente en YouTube. Se encontraron diversos videos de noticias en el canal de YouTube del noticiero local independiente Pazífico Noticias (2014, 2015, 2016) donde se informa sobre la problemática del reconocimiento legal de los terrenos que habita la comunidad. También se visualizó una nota que el mismo noticiero hizo meses antes del proceso de alfabetización digital. Este video (Pazífico Noticias, 2017) fue el resultado de una actividad que se propuso en el marco de esta investigación. Se tramitó ante la producción del noticiero la visita de sus reporteros para que evidenciaran la problemática de la pavimentación de la carretera principal que estaba siendo gestionada por la misma comunidad, exponiendo entonces 
ante la sociedad el abandono estatal, pero también las formas de organización comunitaria que ocurren en las periferias de la ciudad.

También se encontró un video en el canal de la Fundación Internacional Save The Children (Save the Children Colombia, 2013) donde narran el apoyo que la fundación hace en la zona con purificadores de agua y programas de alfabetización sobre nutrición infantil. Cabe aclarar que la constante estética y el discurso que predomina en los primeros videos de Pazífico Noticias y el de la Fundación están relacionados con las carencias y las ausencias en las que vive la comunidad: calles embarradas, casas de bareque, ausencia de legitimidad en los terrenos que habitan, etcétera. Sin embargo, la nota que se logró en el marco de la investigación tuvo un enfoque discursivo diferente. Más allá de denunciar el abandono estatal, se priorizó evidenciar la organización y la autogestión que esta comunidad desarrolla en pos de su bienestar. Por supuesto que la estética visual seguía exponiendo las calles embarradas que falta pavimentar, pero también mostraba la calle principal que ya estaba pavimentada.

También es necesario apuntar que en el desarrollo de las pesquisas anteriores al proceso pedagógico se buscaron proyectos comunicativos preexistentes. En esa pesquisa se encontró el video titulado "video cabildo indígena nasa buenavista" (maria eugenia, 2013), que tiene una duración de 8:54 minutos y contaba con 1718 vistas al momento de nuestra consulta. En el pie del video se puede leer:

Publicado el 21 mayo 2013

LO ANCESTRAL EN EL CABILDO INDÍGENA NASA BUENAVISTA

Danza y música

Tejido

Proyecto Productivo Tejiendo Comunicación

Actualmente en el Cabildo Indígena Nasa Buenavista la mayoría de la población se comunica en su lengua nativa, nasa yuwe; mantiene vivas tradiciones como medicina tradicional, ritualidades, minga, trueque, así como diferentes expresiones artísticas autóctonas como música, danza y tejidos artesanales.

Su interés es fortalecerse como comunidad y mantener vivas las tradiciones de sus ancestros, por lo que están en la búsqueda de implementar procesos de educación propia que contribuyan en ese aspecto y medien los intercambios entre nasas y demás comunidades.

También se visitó su página web oficial (http://cabildoindigenanasabuenavista.hol.es/ actualmente inaccesible), su página de Facebook (https://www. facebook.com/Cabildo-Ind\%C3\%ADgena-Nasa-Buenavista-126003800931380/) y su perfil de Twitter (https://twitter.com/nasabuenavista). 
Al reproducir el video "video cabildo indigena nasa buenavista" (maria eugenia, 2013), se pudo ver una introducción escrita, musicalizada con música instrumental andina que cuenta la siguiente historia:

Cuentan los que saben y dicen que más antes, en la tierra cósmica (espacio), existían dos corrientes de viento, estos vientos corrían y corrían con tal fuerza, pero sin rumbo en el espacio; en esas correrías de pronto los dos se rozaron, los dos vientos eran personas, una del sexo femenino y el otro de sexo masculino. La impresión que se llevaron ambos fue impactante, como queriendo saber el uno del otro. Las dos corrientes de viento se arremolinaron formando un gran círculo como entre una danza, cuando se cansaron de arremolinarse e hicieron una pare. La mujer viento tenía anaco, su cinto asegurado con chumbe, adornado de múltiples figuras, de su cinto resaltaba una vara que en la punta tenía asegurado un manojo de lana del cual ella hilaba, era su vara de mando. El hombre de viento con una ruana negra y pantalón que le daba hasta los tobillos, con sombrero de pindo (hoja de caña brava), con los pies descalzos, en la mano izquierda portaba una vara de mando de oro. Los dos se pararon de extremo a extremo, se dieron una media mirada y sus rostros inmediatamente clavaron sus ojos hacia abajo.

Donde está posición se preguntaron quiénes eran, la mujer habló y dijo: Mi nombre es Uma y soy la mujer que teje la vida. El hombre a su vez dijo: Soy Tay, el hombre que construye la vida. Uma y Tay formaron pareja, nos dieron la vida. Uma es nuestra bisabuela y Tay es nuestro bisabuelo [aclaran: “Texto extraído de KIWE TEN ZA (Guía del pueblo Nasa ante la emergencia)"]. (maria eugenia, 2013, 0:00-1:33)

Se aclara a los lectores que este texto hace referencia a las tradiciones de este pueblo. Por ejemplo, la vestimenta que se describe es la que usan generalmente en los territorios ancestrales o en ocasiones de gala en la ciudad. Cuando se refiere a la "vara de mando" habla de los bastones utilizados por los gobernadores de los cabildos y por los guardias indígenas.

Después de esta introducción cuentan quiénes son. Con imágenes de las casas de bareque enclaustradas en el barro de las altas montañas ellos narran cuál es su procedencia y por qué se encuentran ubicados en esta parte periférica de la ciudad. Las imágenes pixeladas y el sonido tienen problemas técnicos; una voz masculina en off cuenta que este video nace con "el proyecto productivo tejiendo comunicación que es una propuesta que apunta al uso de las nuevas tecnologías de la información" y la comunicación para socializar "la comercialización de artículos propios como mochilas, cinturones, sombreros y otros" (maria eugenia, 2013, 4:33).

También hablan sobre los principios de lucha y resistencia de la guardia indígena y presentan a la gobernadora del momento, la señora María Eugenia Osna y como coordinador de la guardia indígena, al señor Juan Carlos Chindicue, posterior gobernador entrevistado para esta investigación y líder comunitario que participó en la logística y la organización del proceso pedagógico. 
Habiendo conocido sobre los antecedentes de las representaciones mediáticas preexistentes en los medios sociales; se continuó priorizando importancia del reconocimiento sociocultural como base para comenzar a construir un perfil identitario digital: la reivindicación del lugar de origen, de las costumbres tradicionales y de las experiencias vividas en el nuevo territorio urbano; todo ello en articulación con las representaciones mediáticas que estarán en internet gracias al uso posible de las redes sociales digitales, como proceso constructor de la identidad individual, pero también como aporte a la construcción de representaciones comunitarias. Los productos audiovisuales de este primer bloque fueron videos selfie y notas periodísticas sobre las mingas en el barrio. Los asistentes los presentaron, grabaron y subieron a la red.

Para la realización de las notas periodísticas se dividieron dos grupos de trabajo y al interior de cada grupo se repartieron las funciones necesarias (Collazos, 2017a; 2017b); las reporteras que presentaban la nota y quienes hacían la cámara con sus teléfonos celulares. La estética visual priorizó mostrar las formas de trabajo comunitario que estaban ocurriendo ese domingo en la zona. Se construyó la información, de mano de las y los colaboradores de las mingas, para conocer de primera mano los objetivos de los trabajos que se adelantaban. Se trataba de una minga que se ocupaba de rellenar un espacio de la zona para posteriormente hacer una cancha de futbol para los niños y en la otra minga se ocupaban de ampliar la carretera a una zona específica para que puedan pasar los vehículos que traen materiales para la construcción de las casas.

El segundo bloque del proceso pedagógico se ocupó de ampliar los conocimientos frente a los planteamientos básicos sobre la composición de la imagen en foto y en video. Se reconoció que los contenidos en los medios sociales no se caracterizan, necesariamente, por la alta calidad de imagen, sino por los valores simbólicos y funcionales del mensaje. Los ejercicios variaron entre conocer y experimentar la producción de imágenes teniendo en cuenta los planos cinematográficos, el manejo de la luz e incluso se dedicó una sesión técnica a la sensibilidad sonora necesaria para el registro de video; todo ello priorizando siempre la estética propia del barrio y sus personajes. Los árboles plantados al frente de las casas, gallinas caminando por los andenes, las puertas de las casas abiertas, las radios sintonizadas en emisoras caucanas que programan músicas campesinas y populares.

El último bloque estuvo dedicado a conocer el funcionamiento de la red social (Facebook) y la plataforma digital (YouTube) más relevantes (Van Dijck, 2016); así como también se dedicó tiempo para dialogar sobre algunas aplicaciones (Giphy) y otras herramientas que facilitan la producción de memes y gifs. Estos productos visuales exigen propuestas escénicas, por lo que una de las sesiones estuvo 
dedicada a la expresión corporal, generando así un nivel de confianza individual y grupal que aportó a la producción creativa. De esa forma se produjeron gifs que evidencian sus conocimientos laborales con el tejido ("La tejedora Doña Mimia"), la costura ("Mariela") y las artesanías ("Yuli nuestra artesana en Alto Nápoles"). Por su parte, los niños y niñas propusieron expresiones corporales ("\#gifs en Alto Nápoles en red") con bailes y juegos. También se motivó la producción de videos tutoriales (Alto Nápoles en Red, 2017) y se aprendió a crear el canal en YouTube para poder compartirlos, además de descargar videos que pudiesen ser de su interés. Se conversó sobre los nuevos símbolos (emojis, emoticones), signos y lenguajes en los medios sociales.

Finalmente se propuso un ejercicio que reuniera los conocimientos experimentados en el proceso pedagógico y sus historias de vida. Cada participante narró ante la cámara una historia que pudiese ser producida como ficción en un "filminuto" que se realizaría en equipo. Todas las historias estuvieron relacionadas con anécdotas o situaciones vividas en sus lugares de origen o cuando llegaron a su nuevo territorio; relacionaron su pasado con su presente. Estas producciones se encuentran consignadas en un cortometraje documental (Alto Nápoles en Red, 2018) que expone audiovisualmente este proceso de alfabetización digital.

\section{Conclusión}

Las desigualdades históricas por las que estos grupos sociales han transitado no se relacionan fundamentalmente con usar y aplicar las tecnologías como medios en sus vidas para ascender de clase social. El destiempo que vivieron quienes hoy son adultos con la televisión por suscripción es lo que quienes son jóvenes hoy viven con el desconocimiento o el no disfrute de la televisión por demanda y el consumo de series, o lo que quienes son niños hoy viven al no tener dispositivos actualizados, conexiones estables y constantes o simplemente multipantallas que amplíen su experiencia con los consumos culturales mediáticos.

El proyecto pedagógico de alfabetización digital como metodología en las investigaciones sociales y comunicacionales permite proponer que las políticas públicas de las TIC tendrán que incorporar la importancia del territorio como espacio constructor de representaciones digitales.

La posibilidad de que los grupos sociales subalternos produzcan representaciones mediáticas en los medios sociales, a partir de los usos y apropiaciones de las TIC en el marco de experiencias comunitarias, aporta al fortalecimiento de las redes comunitarias y a la construcción de un activismo digital que conlleve a la consolidación de representaciones sociales como productores, difusores y usuarios en las redes sociales y las plataformas digitales. 
Winocur y Sánchez Vilela (2016) compartían que las madres de los niños que recibieron la computadora Ceibal en Uruguay sentían temor de tocar y mucho menos manipular la máquina por miedo a arruinarla. En esta investigación se pudo constatar que si se genera un espacio pedagógico que acerque las posibilidades de usos y apropiaciones que pueden desarrollar a partir de la interacción, los adultos que saltaron de la televisión analógica a los medios sociales, sin pasar por el computador, tendrán confianza de experimentar online porque se requieren habilidades básicas, pero no simples, como saber leer y escribir, para lograr producir y publicar.

La experiencia desarrollada permite vislumbrar que es posible la generación de autorrepresentaciones mediáticas en los medios sociales por parte de grupos subalternos que aporten a la memoria histórica como discurso de luchas y resistencias a la construcción de representaciones sociales propuestas desde el discurso hegemónico. Quizá no para alcanzar la popularidad online o la influencia global, pero sí para aportar a la construcción de la historia social subalterna.

\section{Referencias}

Alto Nápoles en Red (4 de octubre de 2017). Cómo hacer un barco por Maicol Sebastián de Alto Nápoles en Red [archivo de video]. Recuperado de https:// www.youtube.com/watch?v=55srcXYf8yk

Alto Nápoles en Red (11 de octubre de 2018). ALTO NÁPOLES EN RED: Proyecto Pedagógico de Alfabetización Digital [archivo de video]. https://www. youtube.com/watch?v=sb3WEAeDyBU

Buenaventura lidera el comercio exterior. (16 de enero de 1999). El Tiempo. Recuperado de https://www.eltiempo.com/archivo/documento/MAM-862610

Calello, T., y Fritzsche, F. (2007). Internet como mediadora en la construcción de redes de información y comunicación de las asambleas vecinales. En: Quintar, A., Calello, T., y Aprea, G., Los usos de las TICs. Una mirada multidimensional. Buenos Aires: Prometeo Libros/Universidad Nacional General Sarmiento, pp. 85-112.

Cebrelli, A., y Rodríguez, M. G. (2013). ¿Puede (in)visibilizarse al subalterno? Algunas reflexiones sobre las representaciones y los medios. Trampas de la Comunicación y la Cultura, 76-98.

Collazos, H. (1 de octubre de 2017a). Minga comunitaria en Alto Nápoles Bosques 2 [archivo de video]. Recuperado de https://www.youtube.com/ watch?v=yuYjajEyKYE

Collazos, H. (1 de octubre de 2017b). Minga domingo 24 de sept en Alto Nápoles [archivo de video]. Recuperado de https://www.youtube.com/ watch? $=$ oWT8TZRyX8I 
Colombia sigue siendo el país con más desplazados internos: 7,4 millones. (18 de junio de 2017). El Espectador. Recuperado de https://www.elespectador.com/ noticias/el-mundo/colombia-sigue-siendo-el-pais-con-mas-desplazadosinternos-74-millones-articulo-698945

De cuatro millones de desplazados en Colombia, 80 mil viven en Cali. (20 de junio de 2012). El Pueblo. Recuperado de http://elpueblo.com.co/de-cuatromillones-de-desplazados-en-colombia-80-mil-vivenn-en-cali/

Freire, P. (2005). Pedagogía del oprimido. Trad. J. Mellado (50a ed.). México, D. F.: Siglo XXI Editores.

García Canclini, N. (2004). Diferentes, desiguales y desconectados. Mapas de la interculturalidad. Barcelona: Gedisa.

Grimson, A. (2011). Los límites de la cultura. Crítica de las teorías de la identidad. Buenos Aires: Siglo XXI Editores.

Gutiérrez Martín, A. (2003). Alfabetización digital. Algo más que ratones y teclas. Bogotá: Gedisa.

Hall, S. (2010). El surgimiento de los estudios culturales y la crisis de las humanidades. En: Restrepo, E., Walsh, C., y Vich, V., Sin garantías: Trayectorias y problemáticas en estudios culturales. Popayán, Lima, Bogotá, Quito: Envión Editores/Instituto de Estudios Peruanos/Instituto de Estudios Sociales y Culturales Pensar/Universidad Javeriana/Universidad Andina Simón Bolívar Sede Ecuador, pp. 17-28.

Jenkins, H. (1992). Textual Poachers: Television Fans and Participatory Culture. Studies in culture and communication. New York: Routledge.

Jones, R., y Schur, M. (Escritores), y Wright, J. (Director). (21 de octubre de 2016). Nosedive [Episodio de serie de televisión]. En L. Borg (Productora), Black Mirror. Reino Unido: Netflix. Recuperado de https://www.netflix.com/watch/80104627?trackId=14277283\&tctx $=0 \% 2 \mathrm{C} \%$ 2Cc1cd3dc0-4580-4dcb-a0ee-22c0db86d6d1-4034484\%2C\%2C

Los departamentos de Colombia con mayor número de desplazados. (20 de junio de 2016). El Espectador. Recuperado de https://www.elespectador.com/noticias/ nacional/los-departamentos-de-colombia-mayor-numero-de-deplazadoarticulo-638967

maria eugenia. (21 de mayo de 2013). Video cabildo indígena nasa buenavista [archivo de video]. Recuperado de https://www.youtube.com/ watch? $=$ YGSWcAcUOWI

Modonesi, M. (2010). Subalternidad, antagonismo y autonomía: Marxismos y subjetivación política. Buenos Aires: CLACSO. 
Pazífico Noticias. (27 de octubre de 2014). Indígenas Nasa y Yanaconas reclaman tierras en el sur de Cali [archivo de vídeo]. Recuperado de https://www. youtube.com/watch?v=arcSh3KY6J8

Pazífico Noticias. (30 de junio de 2015). Programas de inversión social reclaman en las laderas de Cali [archivo de video]. Recuperado de https://www.youtube. com/watch?v=A-qSGwaNBc8

Pazífico Noticias. (13 de julio de 2016). En Alto Nápoles, 68 familias indígenas se rebelan contra el abandono del Municipio [archivo de video]. Recuperado de https://www.youtube.com/watch?v=BgY39wGSO0A

Pazífico Noticias. (14 de marzo de 2017). Vía de Alto Nápoles se abre paso gracias a la comunidad; la población reclama ayuda de la Alcaldía [archivo de video]. Recuperado de https://www.youtube.com/watch?v=zU14nbFImEI

Quintar, A. (2007). Redes socailes y comunidades virtuales. En: Quintar, A., Calello, T., y Aprea, G., Los usos de las TICs. Una mirada multidimensional. Buenos Aires: Prometeo Libros/Universidad Nacional General Sarmiento, pp. 71-84.

Santos, M. J., y Márquez, M. T. (2003). Trayectorias y estilos tecnológicos. Propuestas para una Antropología de la tecnología. En: Bueno, C., y Santos, M. J., Nuevas tecnologías y cultura. México: Anthropos, pp. 75-97.

Save the Children Colombia. (16 de mayo de 2013). Historia de vida Alto Nápoles [archivo de video]. Recuperado de https://www.youtube.com/ watch?v=HbNWvTtjepM\&t=161s

Van Dijck, J. (2016). La cultura de la conectividad: Una historia crítica de las redes sociales. Buenos Aires: Siglo XXI Editores.

Vega Bendezú, M. (2013). Discursos sobre "raza" y nación en Colombia, 1880-1930. Santiago de Cali: Unidad de Artes Gráficas de la Facultad de Humanidades, Universidad del Valle.

Vio, M., y Fritzsche, F. (2007). Las nuevas Tecnologías dela Información y Comunicación en el territorio: en el umbral de una ciudad sin fin. En: Quintar, A., Calello, T., y Aprea, G., Los usos de las TICs. Una mirada multidimensional. Buenos Aires: Prometeo Libros/Universidad Nacional General Sarmiento, pp. 39-70.

Walsh, C. (2003). Estudios culturales latinoamericanos. Retos desde y sobre la región andina. Quito: Universidad Andina Simón Bolívar Abya-Yala.

Walsh, C. (7 de febrero de de 2017). Oiga Profe. Uniminuto. (F. G. Universitario, Entrevistador) Bogotá D.C. [archivo de video]. Recuperado de https://www. youtube.com/watch? $\mathrm{v}=\mathrm{j} 6 \mathrm{FNfOdh} 7 \mathrm{tU} \&$ feature=youtu.be

Winocur, R., y Sánchez Vilela, R. (2016). Familias pobres y computadoras. Claroscuros de la apropiación digital. Montevideo: Planeta. 